\title{
Service Cooperation Incentive Mechanism in a Dual-Channel Supply Chain under Service Differentiation
}

\author{
Qiaoru Yang*, Meng Zhang \\ School of Management, Chongqing Jiaotong University, Chongqing, China \\ Email: [513357067@qq.com
}

Received 25 March 2015; accepted 21 April 2015; published 28 April 2015

Copyright (C) 2015 by authors and Scientific Research Publishing Inc.

This work is licensed under the Creative Commons Attribution International License (CC BY). http://creativecommons.org/licenses/by/4.0/

c) (i) Open Access

\section{Abstract}

The co-principal-anent models of manufacturer and retailer are built under the complete information and asymmetric information. In addition, the optimal profit sharing and the optimal fixed payment ratio are analyzed and compared in both situations. A motivate mechanism about service effort provided by the manufacturer towards the retailer in a dual-channel supply chain is studied. It implies that the profit of manufacturer under asymmetric information decreases dramatically contrasted to complete information and the retailer can gain profits by providing lower services, thus refusing deficiency of the supply chain.

\section{Keywords}

\section{Supply Chain, Service Differentiation, Dual-Channel, Incentive Mechanism}

\section{Introduction}

With the development of network and growth of customer's passion in network and increment of online shopping orders, channel reconstruction is a measure that more and more enterprises choose to apply [1]. In this case, dual channel supply chain with both the online channel and offline channel is generated, which may lead to serious channel conflicts. The previous researches have indicated that the buy-back strategy [2], price compensation strategy [3], price-discount strategy [4], two parts and promotion level compensation strategy [5] can effectively alleviate channel conflict and conductive for achieving supply chain coordination. But the important role of service level is neglected. In recent years, a certain number of electric business giants (e.g. Jingdong Mall, Su-Ning electronics, and Taobao) use high-quality service rather than intense price war to gain competitive ad-

${ }^{*}$ Corresponding author. 
vantages, and floor, LED and other industries constantly increase capital investment to improve their service level. All of these have indicated that the competition between the enterprises gradually focuses on the service rather than the product. Enterprises that devote themselves to better logistic delivery service, return or replacement service, maintenance and experience service may win customers' trust. As the resulting problems, competition and cooperation with service in a dual channel supply chain have drawn attention within academic and business.

The introduction of an online channel will be beneficial to enhance the manufacturers' barging power and reduce the double marginal benefit, which is the direct theory that supports the rapid development of electronic commerce [6]. Besides the convenience of online shopping, quality of service is another factor that might affect customers' purchasing behavior [7], and opening a direct channel might force the retailers to improve its service level [8]. Considering the significant influence of service on customer purchasing behavior, existing scholars mainly study from two dimensions: service competition and service cooperation. About the service competition, $\mathrm{Xu}$ et al. study the problems of Stackelberg and Nash game decisions when suppliers compete with retailers for service [9]. Similarly, assuming that the costs of service provided by traditional retailers are private informations, Mukhopadhyay respectively studies the optimal decision for service competition in a multi-channel supply chain under information sharing and information un-sharing [10]. Chen et al. formulate that a model of the channel selection of the customer based on service level has effect on demand [11]. Chen and Liu study the optimal decisions for the competition of supply chain members when there are differentiated services. They find that the service competition makes the supply chain with dual-channel superior than the single channel [12]. Sun establishes a service competition model, where customers' channel preference is considered. The study finds that there is service discrimination in supply chain after adding a direct channel, which may be results in reduction of the customers' overall utility and the performance of supply chain system [13]. In addition, Luo et al. study the influence on the service competition and the profit of supply chain when online channel provides value-added service [14]. Dan studies the retailers' optimal service and pricing strategy under noncooperation in dual-channel supply chain [15]. Various decision schemes under the service competition are conducive to improve the performance of supply chain, while the loss of the system efficiency is still large. Therefore, some scholars turn to study the optimal decision under the service cooperation in a dual-channel supply chain. For example, Xiao studies the pricing strategy in a dual-channel supply chain under service cooperation [16]. Luo et al. build a mechanism for coordinating supply chain, which is based on suppliers and retailers to share the cost of services [17]. Kong et al. study the impact of different service costs on the pricing strategy of manufacturers and retailers under service cooperation [18].

Viewing from the above literatures, most of the existing researches that are related to service in dual-channel supply chain are from the perspective of service competition. Researches that are related to service cooperation are gradually in-depth, and most of them are studied under information symmetry. In fact, there are no linear correlations between the increment of service cost and the improvement of service level. And, the motivation to further increase the investment of service cost is very weak for the retailers, especially after the service level reaches a certain level. However, consumers require a mostly perfect level of services, which makes the manufacturer to motivate the retailer to improve its service level when facing with fierce competition. Hence, considering the cooperation model of service that manufacturers entrust all the service of network channel to retailers to fulfill, we study the optimal incentive strategy of manufacturers to motivate retailers to provide high service level for customers of network channel and traditional retail channel.

\section{Model Description}

We consider a dual-channel supply chain composed of one manufacturer and one retailer, and the manufacturer is the leader. The manufacturer sales its products to end customers directly at price $p_{d}$. The retailer buys the products from the manufacturer at wholesale price $w$ and then sales them to customers at retail price $p_{r}$, where $w<p_{r}$. Since the retailer has the location advantage that it can face the customers directly, in order to improve online channel efficiency and customer satisfaction and effectively integrate supply chain resources, the manufacture entrusts electronic channel service (e.g. return and replacement service, advertising, mail notification) to the retailer to fulfill. That is, the retailer not only provides service $s_{r}$ to customers of traditional retail channel, but also provides service $s_{d}$ to customers in online channel. The cost for proving the service is $C(s)=(\eta / 2) s^{2}$. The parameter $\eta$ represents the cost coefficient of the services. The smaller the value of $\eta$, the greater the utility of unit service level. Assuming the service level $s \in[0,1]$, the value of 0 represents the 
retailer does not provide services and 1 represents the retailer provides perfect service. The manufacturer forms a principal-agent relationship with the retailer, in which the manufacturer is the principal and the retailer is the agent. The specific process is shown as Figure 1. Despite it is difficult for the manufacturer to observe service level of the retailer, the sales volume $Q$ generated by the retailer providing service can be known exactly, where $Q=f(s)+\varepsilon$. The production function of service level $s$ is given as $f(s)$, and there are $f^{\prime}(s)>0$ and $f^{\prime \prime}(s)<0$, which indicated that improvement of service level will increase output of service and the increase is decreasing. For analytic simplicity, we assume $f(s)=k s$, where $k$ represents the service output coefficient. Since the retailer provides service for both online channel and traditional channel, there is $k_{d}=k_{r}=k$. Therefore, the sales volume of manufacturer and retailer are respectively given by $Q_{d}=k s_{d}+\varepsilon_{d}$, $Q_{r}=k s_{r}+\varepsilon_{r}$. The parameter $\varepsilon$ represents exogenous and uncertain stochastic variable, such as changes of consumer preference or market environment. Referencing literature [19] and [20], there is $\varepsilon \sim N\left(0, \sigma^{2}\right)$. Depending on the sales volume the manufacturer will pay service reward $t\left(Q_{d}, Q_{r}\right)$ to the retailer in an effort to maximize its profits. Weitman [21] put forward the rationality for using linear contract. Holmstro and Milrgrom [22] also proved that linear contract can optimize the supply chain system. They assumed the incentive function as $t\left(Q_{d}, Q_{r}\right)=\alpha+\beta\left(p_{d} Q_{d}+w Q_{r}\right)$, where $\alpha$ is the fixed payments that the manufacturer pays to the retailer and $\beta \quad(0 \leq \beta \leq 1)$ is the ratio of profit sharing provided by the manufacturer for motivating retailer to improve its service level. Similar to the literature [21], we assume that manufacturer is a risk neutral and the retailer is a risk aversion. It means that retailer can eliminate the risk or the risk condition by changing the plan to protect its interests from damage. We also assume there is no cross-buying between customers.

According to the above assumes, the manufacturer's expected profits is given by

$$
\begin{aligned}
E \pi_{d} & =E\left[p_{d} Q_{d}+w Q_{r}-t\left(Q_{d}, Q_{r}\right)\right] \\
& =E\left[p_{d} Q_{d}+w Q_{r}-\alpha-\beta p_{d} Q_{d}-\beta w Q_{r}\right] \\
& =-\alpha+(1-\beta) p_{d} S_{d}+(1-\beta) w S_{r}
\end{aligned}
$$

The retailer's profits is given by

$$
\pi_{r}=p_{r} Q_{r}-w Q_{r}+t\left(Q_{d}, Q_{r}\right)-C\left(s_{d}, s_{r}\right)
$$

When the retailer is a risk averse, according to literature [21], we use absolute risk aversion to describe the degree of risk aversion of retailer and give the retailer's utility function as classical constant absolute risk aversion function $\mu\left(\pi_{r}\right)=-\mathrm{e}^{-\rho \pi_{r}}$. The parameter $\rho$ is risk aversion measurement. It represents that the retailer is risk appetite type when $\rho<0$ and is risk neutral when $\rho=0$ and is risk aversion when $\rho>0$. We assume the real returns obey normal distribution and the expectation is $m$ and the variance is $n$, namely $\pi_{r} \sim N(m, n)$. Therefore, the retailer's expected utility is given by

$$
E \mu\left(\pi_{r}\right)=\int_{-\infty}^{+\infty}-\mathrm{e}^{-\rho \pi_{r}} f(x) \mathrm{d}_{x}=\int_{-\infty}^{+\infty}-\mathrm{e}^{-\rho \pi_{r}} \frac{1}{\sqrt{2 \pi n}} \mathrm{e}^{-\frac{(x-m)^{2}}{2 n}} \mathrm{~d}_{x}=-\mathrm{e}^{-\rho\left(m-\frac{\rho}{2} n\right)}
$$

where

$$
\begin{aligned}
m & =E \pi_{r}=E\left[p_{r} Q_{r}-w Q_{r}+t\left(Q_{d}, Q_{r}\right)-C\left(s_{d}, s_{r}\right)\right] \\
& =E\left[\left(P_{r}-w\right) Q_{r}+\alpha+\beta p_{d} Q_{d}+\beta w Q_{r}-\frac{\eta}{2}\left(s_{d}^{2}+s_{r}^{2}\right)\right] \\
& =\alpha+k \beta p_{d} s_{d}+\left(p_{r}-w+\beta w\right) k s_{r}-\frac{\eta}{2}\left(s_{d}^{2}+s_{r}^{2}\right),
\end{aligned}
$$

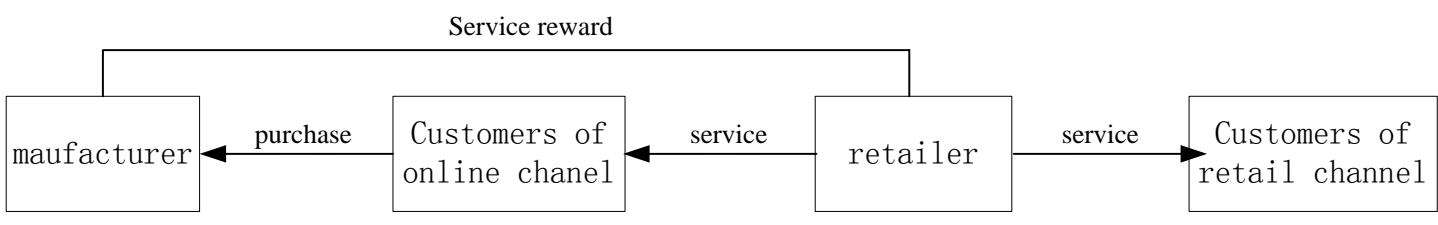

Figure 1. Service cooperation diagram in a dual-channel supply chain. 


$$
n=V\left(\pi_{r}\right)=\left(p_{r}-w+\beta w\right)^{2} \sigma_{r}^{2}+\beta^{2} p_{d}^{2} \sigma_{d}^{2}
$$

The retailer maximizes the expected utility function is equivalent to maximize its certainty equivalent earnings [19]:

$$
\bar{\pi}_{r}=m-\frac{\rho}{2} n=\alpha+k \beta p_{d} s_{d}+\left(p_{r}-w+\beta w\right) k s_{r}-\frac{\eta}{2}\left(s_{d}^{2}+s_{r}^{2}\right)-\frac{\rho}{2}\left(p_{r}-w+\beta w\right)^{2} \sigma_{r}^{2}-\frac{\rho}{2} \beta^{2} p_{d}^{2} \sigma_{d}^{2}
$$

According to retained earnings, the retailer judge whether accept the contract or not. If the certainty equivalent gains $\bar{\pi}_{r}$ are less than the retained earnings $v_{0}$, namely $\bar{\pi}_{r}<v_{0}$, the retailer will not accept the contract. The retailer's participations constraints is

$$
\text { (IR) } \alpha+k \beta p_{d} s_{d}+\left(p_{r}-w+\beta w\right) k s_{r}-\frac{\eta}{2}\left(s_{d}^{2}+s_{r}^{2}\right)-\frac{\rho}{2}\left(p_{r}-w+\beta w\right)^{2} \sigma_{r}^{2}-\frac{\rho}{2} \beta^{2} p_{d}^{2} \sigma_{d}^{2} \geq v_{0}
$$

Faced with any incentive conditions, the retailer will always choose appropriate service level $s_{d}$ and $s_{r}$ to maximize its profits. The retailer's incentive compatibility constraint is given by

$$
\text { (IC) } \max _{\left(s_{d}, S_{r}\right)} \alpha+\beta p_{d} k s_{d}+\left(p_{r}-w+\beta w\right) k s_{r}-\frac{\eta}{2}\left(s_{d}^{2}+s_{r}^{2}\right)-\frac{\rho}{2}\left(p_{r}-w+\beta w\right)^{2} \sigma_{r}^{2}-\frac{\rho}{2} \beta^{2} p_{d}^{2} \sigma_{d}^{2}
$$

\section{Service Cooperation Incentives under Information Symmetry}

In a dual-channel supply chain, information symmetry means the manufacturer, who controls the online channel, knows the information that is related to customers. The information is held by retailers, which includes consumer preference, service cost and service level. In order to maximize its own profits, by controlling the fixed payment and profit sharing ratio the manufacturer will make the retailer to provide a higher service level for the two channels and simultaneously ensure the retailer can get at least the retained earnings. On the contrary, if there is no information superiority, the retailer will certainly ensure the service quality to improve customer service satisfaction in order to avoid damaging its retained earnings. Service cooperation under information symmetry makes supply chain members to achieve a win-win.

Under information symmetry, the retailer's service level $s_{d}$ can be observed by manufacturers. At this point, the incentive compatibility constraint doesn't work, and any level of service $s$ can be achieved by meeting compulsory contract of the participation constraints $I R$. The manufacturer chooses appropriate service level $s_{d}$ and $s_{r}$, fixed payments $\alpha$ and profit sharing ratio $\beta$ to maximize its own profit. The decision-making model is given by

$$
\begin{gathered}
\max _{\alpha, \beta, s_{d}, s_{r}} E \pi_{d}=-\alpha+(1-\beta) p_{d} k s_{d}+(1-\beta) w k s_{r} \\
\text { s.t. (IR) } \alpha+\beta p_{d} k s_{d}+\left(p_{r}-w+\beta w\right) k s_{r}-\frac{\eta}{2}\left(s_{d}^{2}+s_{r}^{2}\right)-\frac{\rho}{2}\left(p_{r}-w+\beta w\right)^{2} \sigma_{r}^{2}-\frac{\rho}{2} \beta^{2} p_{d}^{2} \sigma_{d}^{2} \geq v_{0}
\end{gathered}
$$

According to the decision-making model, if we maximize the manufacturer's profits, equal sign of the participation constraints must be taken. Therefore,

$$
\begin{gathered}
\alpha+\beta p_{d} k s_{d}+\left(p_{r}-w+\beta w\right) k s_{r}-\frac{\eta}{2}\left(s_{d}^{2}+s_{r}^{2}\right)-\frac{\rho}{2}\left(p_{r}-w+\beta w\right)^{2} \sigma_{r}^{2}-\frac{\rho}{2} \beta^{2} p_{d}^{2} \sigma_{d}^{2}=v_{0}, \\
\text { Namely, } \alpha=v_{0}-\beta p_{d} k s_{d}-\left(p_{r}-w+\beta w\right) k s_{r}+\frac{\eta}{2}\left(s_{d}^{2}+s_{r}^{2}\right)+\frac{\rho}{2}\left(p_{r}-w+\beta w\right)^{2} \sigma_{r}^{2}+\frac{\rho}{2} \beta^{2} p_{d}^{2} \sigma_{d}^{2}
\end{gathered}
$$

Substituting (8) into (7), we obtain:

$$
\max E \pi_{d}=-v_{0}+p_{d} k s_{d}+p_{r} k s_{r}-\frac{\eta}{2}\left(s_{d}^{2}+s_{r}^{2}\right)-\frac{\rho}{2}\left(p_{r}-w+\beta w\right)^{2} \sigma_{r}^{2}-\frac{\rho}{2} \beta^{2} p_{d}^{2} \sigma_{d}^{2}
$$

Taking the first order partial derivatives of (9) with respect to $s_{d}, s_{r}$ and $\beta$ respectively, and letting them equal to zero. The optimal service levels under the online channel and the retail channel are $s_{d}^{*}=k p_{d} / \eta$ and $s_{r}^{*}=k p_{r} / \eta$ respectively. The manufacturer's profit sharing ratio is $\beta^{*}=\left(w^{2}-w p_{r}\right) \sigma_{r}^{2} /\left(p_{d}^{2} \sigma_{d}^{2}+w^{2} \sigma_{r}^{2}\right)$. Since $w<p_{r}$, then $\beta^{*}<0$. And the manufacturer's profits will decrease because of 
$\partial_{E \pi_{d}} / \partial_{\beta}=-\rho p_{d}^{2} \sigma_{d}^{2} \beta-\rho \sigma_{r}^{2}\left(p_{r}-w+\beta w\right) w<0$, where $0 \leq \beta \leq 1$, then $\beta^{*}=0$.

When the manufacturers can observe the retailer's service level, in each channel the service level is inversely proportional to the service costs and proportional to the sale pricing of products and has nothing to do with the profit sharing ratio. In this case, the retailer just obtains the part of the fixed payment in the incentive compensation and does not share the profits of online channel.

Substituting $s_{d}^{*}, s_{r}^{*}$ and $\beta^{*}$ into (8) and (9), we can obtain the optimal fixed payments $\alpha^{*}$ paid by the manufacturer and the optimal expected profits of manufacturer. They are given by

$$
\begin{aligned}
E \pi_{d}^{*} & =-v_{0}+\frac{k^{2} p_{r}\left(p_{r}-w\right)}{\eta}-\frac{k^{2}\left(p_{d}^{2}+p_{r}^{2}\right)}{2 \eta}-\frac{\rho \sigma_{r}^{2}\left(p^{r}-w\right)^{2}}{2}+\frac{k^{2} p_{d}^{2}}{\eta}+\frac{k^{2} w p_{r}}{\eta} \\
& =-v_{0}+\frac{k^{2}}{2 \eta}\left(p_{d}^{2}+p_{r}^{2}\right)+-\frac{\rho \sigma_{r}^{2}}{2}\left(p_{r}-w\right)^{2}
\end{aligned}
$$

Since the manufacturer can observe the retailer's service level, if $s_{d}<k p_{d} / \eta$ and $s_{r}<k p_{r} / \eta$, the manufacturer can forcibly make the retailer's profit less than its retained earnings by reducing fixed payments as a punishment.

\section{Cooperation Incentive Services under Asymmetric Information}

The dual-channel supply chain is a value chain composed of different stakeholders, in which the distribution of information is often asymmetrical. Since it is difficult for the manufacturers to observe the retailer's service level, the retailer has more information than the manufacturer. In order to obtain more profits, the retailer often conceals or misrepresents some important and related information from the manufacturer, such as the service requirements and service preferences of consumers and the service costs. The manufacturer can't obtain the service information accurately, which result in compulsory measures losing its efficacy. At this time, the manufacturer will design a corresponding incentive measure to motivate the retailer to improve its service level. Both the participation constraint and incentive compatibility constraint play a role. The decision-making model is reformulated as

$$
\max _{\beta} E \pi_{d}=-\alpha+(1-\beta) p_{d} k s_{d}+(1-\beta) w k s_{r}
$$

$$
\begin{aligned}
& \text { s.t. (IR) } \alpha+\beta p_{d} k s_{d}+\left(p_{r}-w+\beta w\right) k s_{r}-\frac{\eta}{2}\left(s_{d}^{2}+s_{r}^{2}\right)-\frac{\rho}{2}\left(p_{r}-w+\beta w\right)^{2} \sigma_{r}^{2}-\frac{\rho}{2} \beta^{2} p_{d}^{2} \sigma_{d}^{2} \geq v_{0} \\
& \text { (IC) } \max _{\left(s_{d}, s_{r}\right)} \alpha+\beta p_{d} k s_{d}+\left(p_{r}-w+\beta w\right) k s_{r}-\frac{\eta}{2}\left(s_{d}^{2}+s_{r}^{2}\right)-\frac{\rho}{2}\left(p_{r}-w+\beta w\right)^{2} \sigma_{r}^{2}-\frac{\rho}{2} \beta^{2} p_{d}^{2} \sigma_{d}^{2}
\end{aligned}
$$

The retailer seeks the optimal service level $s_{d}$ and $s_{r}$ to achieve maximum profits, according to the firstorder conditions of the incentive compatibility, we obtain

$$
\frac{\partial \bar{v}}{\partial s_{d}}=\beta k p_{d}-\eta s_{d}=0, \frac{\partial \bar{v}}{\partial s_{r}}=\left(p_{r}-w+\beta w\right) k-\eta s_{r}=0 .
$$

By solving the above two equation, we can obtain the optimal service levels provided by the retailer for network channel and traditional channel under information asymmetry, which respectively given as $\bar{s}_{d}^{*}=\bar{\beta}^{*} k p_{d} / \eta$ and $\bar{s}_{r}^{*}=\left(p_{r}-w+\bar{\beta}^{*} w\right) k / \eta$.

Similar to the case that the information is symmetry, the retailer will take the equations of the participation constraint, so substituting (7), $\bar{s}_{d}^{*}$ and $\bar{s}_{r}^{*}$ into (11), we can obtain

$$
\begin{aligned}
\max _{\beta} E \pi_{d}= & -v_{0}+\frac{\beta k^{2} p_{d}^{2}}{\eta}+\frac{k^{2} p_{r}\left(p_{r}-w+\beta w\right)}{\eta}-\frac{k^{2}}{2}\left[\frac{\beta^{2} p_{d}^{2}}{\eta}+\frac{\left(p_{r}-w+\beta w\right)^{2}}{\eta}\right] \\
& -\frac{\rho}{2}\left(p_{r}-w+\beta w\right)^{2} \sigma_{r}^{2}-\frac{\rho}{2} \beta^{2} p_{d}^{2} \sigma_{d}^{2}
\end{aligned}
$$

Taking the first order partial derivatives of (12) with respect to $\beta$ and letting it equal to zero, the optimal profit sharing ratio under asymmetric information is given by 


$$
\bar{\beta}^{*}=\frac{k^{2}\left(p_{d}^{2}+w^{2}\right)-\eta \rho \sigma_{r}^{2}\left(w p_{r}-w^{2}\right)}{k^{2}\left(p_{d}^{2}+w^{2}\right)+\eta \rho\left(p_{d}^{2} \sigma_{d}^{2}+w^{2} \sigma_{r}^{2}\right)}
$$

Viewing from the Equation (13), when manufacturers can't observe the retailer's service level, the service level that the retailer provides to the customer of online channel is proportional with the profit sharing ratio and inversely proportional with service costs. When the profits sharing ratio is improved, there must be a corresponding increase in the service level provided to online channel. The service level of retail channel is related to the retail price and wholesale price. In the retail channel, the customers will enjoy a higher service level when the difference between the wholesale price and the retail price is large, and the retail channel also will provide higher service level when the profit sharing ratio is improved. Meanwhile, the retailers' risk preferences $\rho$ have influence on the profit sharing ratio of the retailer. The more conservative the retailer, the lower the profitsharing ratio shared from manufacturers will be.

Substituting $\bar{s}_{d}^{*}, \bar{s}_{r}^{*}$ and $\bar{\beta}^{*}$ into (11) or (12), the optimal fixed payment that the retailer gain from the manufacturer and the optimal profits of the manufacturer under information asymmetry respectively are

$$
\begin{aligned}
\bar{\alpha}^{*}= & v_{0}+\left(\frac{\rho \sigma_{d}^{2}}{2}-\frac{k^{2}}{2 \eta}\right)\left(\bar{\beta}^{*}\right)^{2} P_{d}^{2}-\left(\frac{k^{2}}{2 \eta}-\frac{\rho \sigma_{r}^{2}}{2}\right)\left(P_{r}-\omega+\bar{\beta}^{*} \omega\right)^{2} \\
= & v_{0}+\left(\frac{\rho \sigma_{d}^{2}}{2}-\frac{k^{2}}{2 \eta}\right) P_{d}^{2}\left[\frac{k^{2}\left(p_{d}^{2}+w^{2}\right)-\eta \rho \sigma_{r}^{2}\left(w p_{r}-w^{2}\right)}{k^{2}\left(p_{d}^{2}+w^{2}\right)+\eta \rho\left(p_{d}^{2} \sigma_{d}^{2}+w^{2} \sigma_{r}^{2}\right)}\right]^{2} \\
& -\left(\frac{k^{2}}{2 \eta}-\frac{\rho \sigma_{r}^{2}}{2}\right)\left[P_{r}-\omega+\frac{k^{2}\left(p_{d}^{2}+w^{2}\right)-\eta \rho \sigma_{r}^{2}\left(w p_{r}-w^{2}\right)}{k^{2}\left(p_{d}^{2}+w^{2}\right)+\eta \rho\left(p_{d}^{2} \sigma_{d}^{2}+w^{2} \sigma_{r}^{2}\right)} \omega\right]^{2} \\
\bar{E} \pi_{d}{ }^{*}= & -v_{0}+\left(\frac{k^{2} \bar{\beta}^{*}}{\eta}-\frac{\rho \sigma_{d}^{2}\left(\bar{\beta}^{*}\right)^{2}}{2}-\frac{k^{2}\left(\bar{\beta}^{*}\right)^{2}}{2 \eta}\right) p_{d}^{2} \\
& +\left(\frac{k^{2}}{2 \eta}-\frac{\rho \sigma_{r}^{2}}{2}\right)\left(P_{r}-\omega+\bar{\beta}^{*} \omega\right)^{2}+\frac{k^{2} w\left(1-\bar{\beta}^{*}\right)}{\eta}\left(P_{r}-\omega+\bar{\beta}^{*} \omega\right)
\end{aligned}
$$

\section{Analysis about the Impact of Different Services on Cooperative Mechanisms}

The distinction between online channel and traditional channel gives rise to the difference of customer service experience in each channel. The online channel brings customers more product information, and the work hours more convenient and unlimited, while the traditional channel provides customers with the lower risk, perceived experience in store and without distribution. Different service experience in the two channels will alter the customer purchasing behavior and lead to the change of demand structure of the market.

On the premise of service cooperation, the optimal service level provided to the two channels by the retailer respectively are $s_{d}^{*}=k p_{d} / \eta$ and $s_{r}^{*}=k p_{r} / \eta$ when information symmetry and respectively are

$\bar{s}_{d}^{*}=\bar{\beta}^{*} k p_{d} / \eta$ and $\bar{s}_{r}^{*}=\left(p_{r}-w+\bar{\beta}^{*} w\right) k / \eta$ when information asymmetry. According to these, under the conditions of service cooperation, whether the information is symmetric or not, the manufacture and the retailer can profit more when the retailer provides differentiated services $\left(s_{d} \neq s_{r}\right)$ for the two channels.

The following, we will further analyze whether the information symmetry has impact on profits of manufacturer, retailer and supply chain system when the manufacturer cooperates with the retailer who will provide differentiated services. The difference between manufacturer's profits under information symmetry and information asymmetry is

$$
\Delta E \pi_{d}=E \pi_{d}^{*}-\bar{E} \pi_{d}^{*}=\frac{k^{2}\left(1-\bar{\beta}^{*}\right)^{2}}{2 \eta}\left(p_{d}^{2}-w^{2}\right)+\frac{\rho}{2}\left(\bar{\beta}^{*}\right)^{2} \sigma_{d}^{2} p_{d}^{2}+\frac{(1-\beta)^{2}}{\eta} w^{2}+\frac{\rho}{2} \sigma_{r}^{2} \bar{\beta}^{*} w\left(2 p_{r}-2 w+\bar{\beta}^{*} w\right)
$$


According to the limits that $0<\beta<1, w<p_{r}, w<p_{d}$, we know $\Delta E \pi_{d}$ is constantly positive. Therefore, because of information asymmetry the manufacturer suffers losses. Using the advantage of facing customer directly the retailer delivers incomplete information to the manufacturer, which making it difficult for manufacturer to predict market demand accurately, thereby it is difficult to make scientific and rational decisions of production and transportation.

Different with manufacturer, the retailer's profits remain unchanged whether information is symmetric or not. The reason is that the retailer's certainty equivalent gains unchanged. However, the retailer can still profit. Under information asymmetry service level of the two channels both are lower than that under information symmetry, which allows the retailer to obtain unchanged profits by providing a lower service level. In other words, actually, the retailer's profits disguisedly increase under the existing service level. Because of the reduction of the manufacturer's profits, the supply chain system's profits also reduce.

The retailer's service costs directly influence the manufacturer's profits under the condition of cooperation. Whether the information is symmetric or not the manufacturer's profits will decrease with the increase of service cost coefficient $\eta$. But when information is asymmetric, the reduction of service costs enable the retailer to obtain a greater profits sharing ratio $(\partial \beta / \partial \eta<0)$. Because of information asymmetry, the manufacturer loses more profits $(\partial \Delta E / \partial \eta<0)$. Accordingly, the manufacturers will set up efforts to collect more information that the market demands.

\section{Numerical Analysis}

This section will verify the impact of service costs on manufacturers' profits in the cases of information symmetry and asymmetry using numerical examples. Assuming that a kind of product is sold through dual channel, and $p_{d}=0.5, p_{r}=0.6, w=0.3, v=0.1, \sigma_{d}^{2}=2, \sigma_{r}^{2}=1.5, \rho=0.5, k=0.5$. Using Matlab7.0 for simulation calculations, we can get changes of the manufacturer's profits with different service level under the conditions of information symmetry and asymmetry, and these are shown as Figures 2-5.

In Figure 2 and Figure 3, whether information is symmetric or not, the manufacturer's profits always decrease with the increase of the retailer's service costs, but under information asymmetry the decrease is only slightly higher than that under information symmetry. This confirms the assertion that there is no seriously influence on manufacturer's profits when the retailer conceals service information.

Viewing from Figure 4 and Figure 5, the service level provided by retailers to the traditional channel is always higher than that to the direct online channel, and with the increase of service costs, differentiation of service level will become increasingly obvious, especially in the case of information asymmetry.

\section{Conclusion}

With the continuous improvement of market, customer service has become an important factor that strongly in-

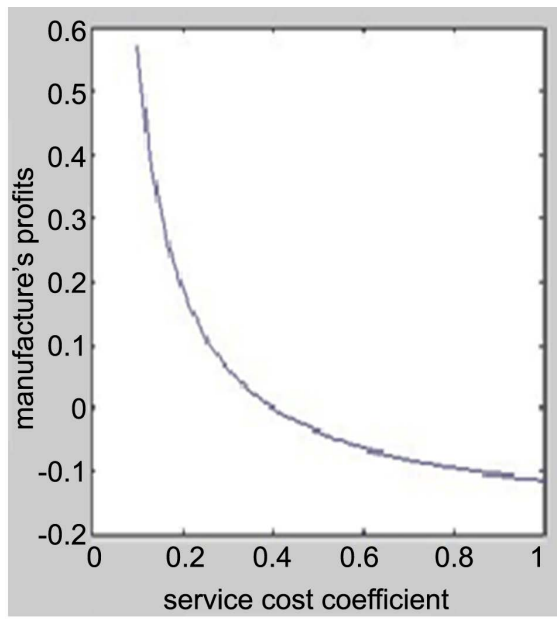

Figure 2. Manufacture's profits under, information symmetry information asymmetry. 


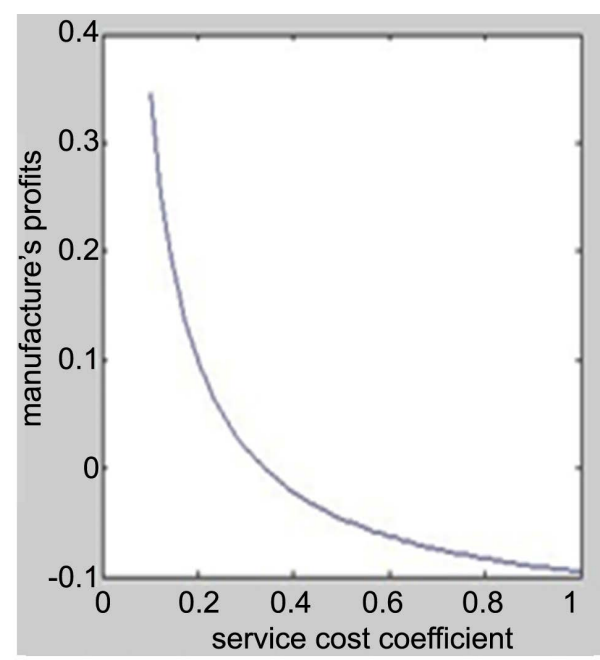

Figure 3. Manufacture's profits under, information symmetry information asymmetry.

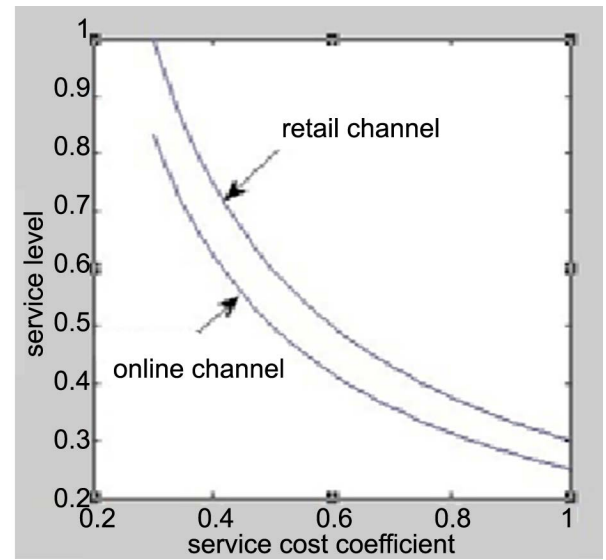

Figure 4. Service level under information symmetry.

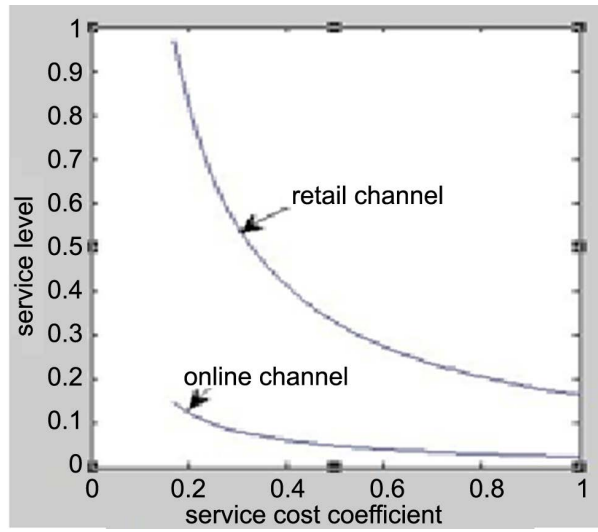

Figure 5. Service level under information asymmetry.

fluences the interests of supply chain members. Assuming that there are no cross-buying in dual-channel supply chain composed of one manufacturer and one retailer, the incentives mechanism when the manufacturer entrusts online channel service to the retailer is studied. We establish a principal-agent model to solve it and the optimal fixed payment and optimal sharing ratio are given. The authors also compare and analyze the relationship be- 
tween service levels of online channel and retail channel and the impact of service costs and uncertain factors of market on manufacturer profits. The results show that the decrease of the retailer's service cost and the increase of uncertain factors in market will reduce the manufacturer's profits. It is worth noted that some assumptions in this text are very strict. For example, cross-buying behavior does not exist, which is different from the actual market situation. Thus, further and perfect researches are needed.

\section{References}

[1] Liu, S.J. (2002) The Factors and Develop Ideas of Personnel Leasing. Human Resources, 4, 18-20.

[2] Yao, D.Q., Yue, X.H. and Wang, X.Y. (2005) The Impact of Information Sharing on a Returns Policy with the Addition of a Direct Channel. International Journal of Production Economics, 97, 196-209. http://dx.doi.org/10.1016/j.ijpe.2004.08.006

[3] Kurata, H., Yao, D.Q. and Liu, J.J. (2007) Pricing Polices under Direct vs. in Direct Channel Competition and National vs. Store Brand Competition. European Journal of Operation Research, 180, 262-281. http://dx.doi.org/10.1016/j.ejor.2006.04.002

[4] Cai, G., Zhang, Z.G. and Zhang, M. (2009) Game Theoretical Perspectives on Dual Channel Supply Chain Competition with Price Discounts and Pricing Schemes. International Journal of Production Economics, 117, 80-96. http://dx.doi.org/10.1016/j.ijpe.2008.08.053

[5] Chen, S.Z., Xiong, Z.K. and Liang, X. (2009) Contract Design for a Dual-Channel Supply Chain Coordination with Incentive Compensation. Chinese Journal of Management Science, 17, 64-75.

[6] Chiang, W.K., Chhajed, D. and Hess, J.D. (2003) Direct Marketing, Indirect Profits: A Strategic Analysis of DualChannel Supply-Chain Design. Management Science, 49, 1-20. http://dx.doi.org/10.1287/mnsc.49.1.1.12749

[7] Rohm, A.J. and Swaminathan, V. (2004) A Typology of Online Shoppers Based on shopping Motivations. Journal of Business Research, 57, 748-757. http://dx.doi.org/10.1016/S0148-2963(02)00351-X

[8] Yao, D.Q. and Liu, J.J. (2005) Competitive Pricing of Mixed Retail and Etail Distribution Channels. Omega, 33, 235247. http://dx.doi.org/10.1016/j.omega.2004.04.007

[9] Xu, M.H., Yu, G. and Zhang, H.Q. (2006) Game Analysis in a Supply Chain with Service Provision. Journal of Management Science in China, 9, 18-27.

[10] Mukhopadhyay, S.K., Yao, D.Q. and Yue, X. (2008) Information Sharing of Value-Adding Retailer in a Mixed Channel Hi-Tech Supply Chain. Journal of Business Research, 61, 950-958. http://dx.doi.org/10.1016/j.omega.2004.04.007

[11] Chen, K.Y., Kaya, M. and Özalp, Ö. (2008) Dual Sales Channel Management with Service Competition. Manufacturing \& Service Operations Management, 10, 654-675. http://dx.doi.org/10.1287/msom.1070.0177

[12] Chen, Y.G. and Liu, N. (2010) Dual-Channel Supply Chain Competition Strategy with Service Differentiation. Computer Integrated Manufacturing Systems, 16, 2484-2488.

[13] Sun, Y.H., Tu, Y.J. and Xu, X.Y. (2011) The Service Competition Model Based on Customer Channel Preference. Journal of Management Science, 24, 62-70.

[14] Luo, M.L., Li, G. and Sun, L.Y. (2011) Competition in a Dual-Channel Supply Chain with Add-Value Services. Industrial Engineering and Management, 16, 37-44.

[15] Dan, B., Xu, G.Y. and Liu, C. (2012) Pricing Policies in a Dual-Channel Supply Chain with Retail Services. Production Economics, 139, 312-320. http://dx.doi.org/10.1016/j.ijpe.2012.05.014

[16] Xiao, J., Dan, B. and Zhang, X.M. (2010) Service Cooperation Pricing Strategy between Manufacturers and Retailers in Dual-Channel Supply Chain. Systems Engineering-Theory \& Practice, 30, 2203-2211.

[17] Luo, M.L., Li, G. and Sun, L.Y. (2011) Competition in a Dual Channel Supply Chain with Service Spill-Over Effect. Journal of Systems \& Management, 20, 648-657.

[18] Kong, Q.H., Xing, W. and Shi, X.M. (2012) On Problem of Dual-Channel Supply Chain Pricing with Service Strategy. Commercial Research, 418, 114-118.

[19] Laffont, J.J. and Martimort, D. (2002) The Theory of Incentives: The Principal Agent Model. China Renmin University Press, Beijing.

[20] Zhang, W.Y. (2012) The Game Theory and Information Economy. Shanghai People’s Publishing House, Shanghai, 239-256.

[21] Weitzman, M.L. (1980) Efficient Incentive Contracts. The Quarterly Journal of Economics, 94, 719-730. http://dx.doi.org/10.2307/1885665

[22] Holmstrom, B. and Milgrom, P. (1987) Aggregation and Linearity in the Provision of Intertemporal Incentives. Econometrica, 55, 303-328. http://dx.doi.org/10.2307/1913238 